\title{
Choroidal involvement in non-infectious posterior scleritis
}

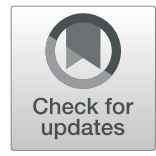

Sandra Vermeirsch(1), Ilaria Testi and Carlos Pavesio ${ }^{*}$

\begin{abstract}
Purpose: To provide a comprehensive overview of choroidal involvement in non-infectious posterior scleritis; including different imaging modalities and their clinical usefulness.

Methods: Narrative review.

Results: Posterior scleritis is an uncommon yet potentially sight-threatening inflammation of the sclera. During the disease process, inflammation can spread to the adjacent choroid, causing different manifestations of choroidal involvement: (1) increased choroidal thickness, (2) choroidal vasculitis, (3) presentation as a choroidal or subretinal mass in nodular posterior scleritis, and (4) choroidal folds, choroidal effusion and exudative retinal detachment.

Conclusions: Clinical characteristics and multimodal imaging can aid in diagnosing and monitoring disease progression and response to treatment in non-infectious posterior scleritis with choroidal involvement.

Keywords: Posterior scleritis, Choroid, Choroidal involvement, Choroidal thickness, Choroidal vasculitis, Choroidal mass, Choroidal folds, Exudative retinal detachment
\end{abstract}

\section{Introduction}

Posterior scleritis is a potentially sight-threatening, inflammatory process of the sclera that primarily involves the posterior segment of the eye [1]. It is an uncommon condition, affecting between 2.0 and $17.7 \%$ of all scleritis patients in retrospective epidemiological studies [2-12]. Posterior scleritis is reported to have a female preponderance in the majority of case series and can occur in all decades of life (Table 1) [13-28].

Diffuse and nodular forms of posterior scleritis can be discerned $[25,29]$. The majority of patients with posterior scleritis present with unilateral involvement without associated active anterior scleritis, although more than half of all patients is reported to develop clinically apparent anterior scleritis at some point during follow-up [21, $24,25]$. The most commonly reported symptoms on presentation are periocular pain and headache (typically worse at night and waking the patient from sleep early in the morning), pain on ocular movement, and blurred

* Correspondence: c.pavesio@nhs.net

Moorfields Eye Hospital, National Health Service Foundation Trust, 162 City Rd, Old Street, London EC1V 2PD, UK

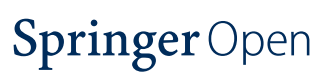

vision $[18,21,24,25,29]$. It is important to note that painless presentations can occur. Systemic disease associations, including rheumatoid arthritis, systemic lupus erythematous and systemic vasculitis, are found in less than half of all patients $[18,21,24,25]$. The most frequently reported clinical findings are conjunctival chemosis or hyperemia, anterior scleritis, anterior uveitis, choroidal folds, optic nerve swelling, serous retinal detachment and macular oedema [15, 18, 21, 24, 25]. Other presenting findings include a circumscribed subretinal mass in nodular posterior scleritis $[13,15,16,18$, $24]$, annular choroidal detachment [15, 24], raised intraocular pressure including angle-closure glaucoma due to ciliochoroidal effusion [17, 30-34], retinal pigment epithelium (RPE)-rip [35], contiguous involvement of retinal artery and vein causing occlusion of the vessels [3638], or stellate neuroretinitis [39]. As posterior scleritis can present with a wide range of symptoms and clinical findings, it can easily be overlooked or confused with other disease entities such as Vogt-Koyanagi-Harada disease $(\mathrm{VKH})$, central serous chorioretinopathy $(\mathrm{CSC})$ or

(c) The Author(s). 2021 Open Access This article is licensed under a Creative Commons Attribution 4.0 International License, which permits use, sharing, adaptation, distribution and reproduction in any medium or format, as long as you give appropriate credit to the original author(s) and the source, provide a link to the Creative Commons licence, and indicate if changes were made. The images or other third party material in this article are included in the article's Creative Commons licence, unless indicated otherwise in a credit line to the material. If material is not included in the article's Creative Commons licence and your intended use is not permitted by statutory regulation or exceeds the permitted use, you will need to obtain permission directly from the copyright holder. To view a copy of this licence, visit http://creativecommons.org/licenses/by/4.0/. 
Table 1 Literature review of case series on posterior scleritis

\begin{tabular}{|c|c|c|c|c|}
\hline Authors (year of publication) & Country & Number of patients & Age at presentation (years) & M:F ratio \\
\hline Agrawal et al. (2016) [13] ${ }^{\text {a }}$ & UK & 11 & Mean 57 (range 30-84) & $1: 4.5$ \\
\hline Ando et al. (2020) [14] & Japan & 10 (13 eyes) & Mean 50.1 (range 17-77) & $1: 1$ \\
\hline Benson W. (1988) [15] & US & 43 & Median 38 (range 8-75) & $1: 2.1$ \\
\hline Benson et al. (1979) [16] & US & 7 & Median 43 (range 30-55) & (only F) \\
\hline Biswas et al. (1998) [17] & India & 8 & Median 35.5 (range 11-46) & $1: 1$ \\
\hline Calthorpe et al. (1988) [18] & UK & 47 & Mean 49 (range 12-87) & $1: 1.5$ \\
\hline Cheung et al. (2012) [19] ${ }^{b}$ & Singapore & 13 (20 eyes) & Median 11.5 (range 5-16) & $1: 1.6$ \\
\hline Dong et al. (2019) [20] ${ }^{c}$ & China & 23 & Mean 29.5 (range 19-57) & $1: 1.3$ \\
\hline Gonzalez-Gonzalez et al. (2014) [21] & Spain and US & 31 & Mean 43.6 (range 12-77) & $1: 5.2$ \\
\hline Gonzalez-Lopez et al. (2016) [22] ${ }^{d}$ & UK and India & 18 & Median 48 (range 17-83) & $1: 3.5$ \\
\hline Kumar et al. (2018) [23] & India & 18 & Mean 41.2 (range 26-63) & $1: 1.2$ \\
\hline Lavric et al. (2016) [24] & UK and India & 114 & Mean 45.9 & $1: 2.5$ \\
\hline McCluskey et al. (1999) [25] & UK & 137 & Mean 49.3 (range 11-84) & $1: 1.8$ \\
\hline Rosenbaum et al. (1993) [26] & US & 6 & Mean 50.3 (range 33-64) & $1: 0.2$ \\
\hline Singh et al. (1986) [27] & Germany and US & 9 (12 eyes) & Mean 40.2 (range 14-68) & $1: 0.2$ \\
\hline Wald et al. (1992) [28] b & US & 4 & Mean 11.8 (range 10-14) & (only M) \\
\hline
\end{tabular}

${ }^{a}$ Nodular posterior scleritis; ${ }^{b}$ Only children included; ${ }^{c}$ Posterior scleritis presenting with serous retinal detachment; ${ }^{d}$ Bilateral posterior scleritis

choroidal malignancies. A high level of suspicion is thus warranted. Clinical characteristics and multimodal imaging findings of differential diagnoses of posterior scleritis are described in Table 2.

The diagnosis of posterior scleritis can be aided by Bscan ultrasonography, which typically shows a $\mathrm{T}$-sign due to the presence of fluid in the sub-Tenon's space, along with increased thickness of the posterior coats $(>2.0 \mathrm{~mm})$ $[21,24,25,29]$. It is important to note that the absence of a T-sign does not exclude the diagnosis [24]. Magnetic resonance imaging (MRI) is known to have excellent soft tissue contrast and can be useful when the ultrasound findings are inconclusive. Scleral enhancement is the most commonly identified MRI-finding in posterior scleritis [42]. This can only be identified with the use of gadolinium contrast, thus the use of contrast is essential in suspected posterior scleritis. Scleral thickening and focal periscleral cellulitis are other important imaging findings on MRI [42-44]. CT imaging can also be useful in case of contraindications to MR imaging [42].

As posterior scleritis may cause pain and visual loss, and the risk of recurrences is high, early and aggressive treatment is recommended [11, 24]. Systemic nonsteroidal anti-inflammatory drugs (NSAIDs) are the preferred first-line treatment in mild cases of anterior nonnecrotizing scleritis, but in posterior involvement the use of systemic steroids (orally or intravenously) is usually recommended in view of the fact that it is not possible to predict the risk of visual loss even in cases that may appear to be mild in presentation [29, 45]. Immunosuppressive agents should be considered if the response to steroids is unsatisfactory, if long-term steroid sparing therapy is needed, or in case of recurrences [29, 45]. Methotrexate, Azathioprine and Mycophenolate Mofetil are most commonly used, while cyclosporin, cyclophosphamide, chlorambucil, and biologics such as anti-tumor necrosis factor alpha (anti-TNF- $\alpha$ ) (e.g. Infliximab) or antiCD-20 (e.g. Rituximab) can also be considered [45].

This review article aims to provide a comprehensive overview of choroidal involvement in non-infectious posterior scleritis, including different imaging modalities and their clinical usefulness in diagnosing and monitoring patients with posterior scleritis.

\section{Methods}

A literature search of PubMed was performed using the search terms 'posterior scleritis', 'scleritis', 'choroid', 'choroidal, 'thickness', 'mass', 'vasculitis', and 'exudative retinal detachment'. Only English articles were included, and no time restrictions were applied. Studies reporting solely infectious causes were excluded based on title and abstract, as infectious scleritis is outside the scope of this review. The references from the selected articles were scrutinized and additional relevant manuscripts were included.

\section{Results of literature search and discussion}

Scleral inflammation can spread to the adjacent choroid and cause secondary choroidal involvement. Histopathological evidence on enucleated globes or biopsy specimens of posterior scleritis cases showed choroidal involvement in all seven cases reported by Calthorpe et al. [18] The choroid was reported to be thickened 
Table 2 Differential diagnosis of posterior scleritis

\begin{tabular}{|c|c|c|c|c|}
\hline & Posterior scleritis & $\begin{array}{l}\text { Central serous chorioretinopathy } \\
\text { (CSC) }[15,40]\end{array}$ & $\begin{array}{l}\text { Vogt-Koyanagi-Harada } \\
\text { disease (VKH) [15, 40, } \\
\text { 41] }\end{array}$ & Choroidal melanoma ${ }^{a}[13,40]$ \\
\hline \multicolumn{5}{|c|}{ Typical clinical characteristics } \\
\hline Laterality & Mostly unilateral & Unilateral or bilateral & $\begin{array}{l}\text { Bilateral (second eye } \\
\text { involvement within } 2 \\
\text { weeks) }\end{array}$ & Unilateral \\
\hline $\begin{array}{l}\text { Presenting } \\
\text { symptoms }\end{array}$ & $\begin{array}{l}\text { Acute painful vision loss } \\
\text { (typically worse at night or on } \\
\text { eye movements) }\end{array}$ & Painless vision loss & $\begin{array}{l}\text { Blurred vision, } \\
\text { photophobia, ocular pain. } \\
\text { Associated systemic } \\
\text { symptoms depending on } \\
\text { disease stage. }\end{array}$ & $\begin{array}{l}\text { Painless visual changes (rarely } \\
\text { painful when necrotic). Can be } \\
\text { asymptomatic. }\end{array}$ \\
\hline $\begin{array}{l}\text { Associated } \\
\text { clinical } \\
\text { signs }\end{array}$ & $\begin{array}{l}\text { Anterior scleritis, anterior uveitis, } \\
\text { vitreous inflammation, choroidal } \\
\text { folds, optic disc edema. }\end{array}$ & $\begin{array}{l}\text { Round/oval serous retinal } \\
\text { detachment with or without } \\
\text { detachment of retinal pigment } \\
\text { epithelium (RPE), RPE changes } \\
\text { (focal or multifocal). } \\
\text { No associated inflammatory signs. }\end{array}$ & $\begin{array}{l}\text { Granulomatous anterior } \\
\text { uveitis, vitritis, diffuse } \\
\text { choroiditis, Dalen-Fuchs } \\
\text { nodules, sunset glow fun- } \\
\text { dus, optic disc edema. } \\
\text { Frequent associated skin } \\
\text { changes, CNS findings } \\
\text { (incl. Cerebrospinal fluid } \\
\text { pleocytosis) }\end{array}$ & $\begin{array}{l}\text { Pigmented or amelanotic } \\
\text { elevated choroidal mass, } \\
\text { lipofuscin often present. Serous } \\
\mathrm{RD} \text { and/or sentinel vessel } \\
\text { possible. Associated } \\
\text { inflammation rare. }\end{array}$ \\
\hline $\begin{array}{l}\text { Response } \\
\text { to steroids }\end{array}$ & $\begin{array}{l}\text { Improvement of pain and } \\
\text { imaging findings }\end{array}$ & $\begin{array}{l}\text { Can worsen presenting signs and } \\
\text { symptoms }\end{array}$ & $\begin{array}{l}\text { Improvement of pain and } \\
\text { imaging findings }\end{array}$ & None \\
\hline \multicolumn{5}{|c|}{ Multimodal imaging findings } \\
\hline $\begin{array}{l}\text { B-scan } \\
\text { ultrasound }\end{array}$ & $\begin{array}{l}\text { T-sign, increased thickness of the } \\
\text { posterior coats (> } 2.0 \mathrm{~mm} \text { ), } \\
\text { nodular subtype possible (sessile } \\
\text { or dome shaped lesion with } \\
\text { high internal reflectivity) }\end{array}$ & Serous RD possible & Serous RD possible & $\begin{array}{l}\text { Dome-shaped or mushroom- } \\
\text { shaped choroidal lesion with typ- } \\
\text { ically low to medium internal re- } \\
\text { flectivity. Choroidal excavation } \\
\text { and serous RD possible. }\end{array}$ \\
\hline$O C T$ & $\begin{array}{l}\text { Choroidal folds, serous retinal } \\
\text { detachment, macular oedema }\end{array}$ & $\begin{array}{l}\text { Subretinal fluid (SRF) (can be } \\
\text { multifocal), RPE-detachment(s), } \\
\text { intraretinal fluid (IRF) possible, atro- } \\
\text { phic RPE-changes possible }\end{array}$ & $\begin{array}{l}\text { Serous retinal detachment } \\
\text { with typical fibrinous septa }\end{array}$ & $\begin{array}{l}\text { Dome-shaped solid choroidal } \\
\text { mass, accompanying SRF } \\
\text { possible }\end{array}$ \\
\hline EDI-OCT & $\begin{array}{l}\text { Localized choroidal thickening in } \\
\text { affected eye in acute stages, } \\
\text { choroidal thinning after } \\
\text { treatment or in advanced stages }\end{array}$ & $\begin{array}{l}\text { Diffuse choroidal thickening, } \\
\text { dilated large vessels in Haller's layer } \\
\text { with thinning of overlying smaller } \\
\text { vessels in Sattler's layer and } \\
\text { choriocapillaris }\end{array}$ & $\begin{array}{l}\text { Choroidal thickening in } \\
\text { acute stages, choroidal } \\
\text { thinning after treatment or } \\
\text { in advanced stages }\end{array}$ & $\begin{array}{l}\text { Dome-shaped solid choroidal } \\
\text { mass with smooth surface }\end{array}$ \\
\hline$F A$ & $\begin{array}{l}\text { Early pinpoint leaks with late } \\
\text { pooling in cases with subretinal } \\
\text { fluid }\end{array}$ & $\begin{array}{l}\text { Focal leak in acute phase (typically } \\
\text { described as 'ink blot' or } \\
\text { 'smokestack' leakage pattern). } \\
\text { Multifocal leakage ('hot spots') and } \\
\text { pooling under detached RPE } \\
\text { possible. Disc leak absent. }\end{array}$ & $\begin{array}{l}\text { Focal areas of delayed } \\
\text { choroidal perfusion, } \\
\text { multiple pinpoint regions } \\
\text { of leakage at the RPE-level, } \\
\text { disc hyperfluorescence }\end{array}$ & $\begin{array}{l}\text { Multiple areas of pinpoint } \\
\text { leakage }\end{array}$ \\
\hline ICGA & $\begin{array}{l}\text { Choroidal vasculitis, zonal } \\
\text { choroidal hyperfluorescence ( } \pm \\
\text { pinpoint leakage), choroidal } \\
\text { perfusion delay, enlargement of } \\
\text { draining choroidal veins, and } \\
\text { hypofluorescent dark dots }\end{array}$ & $\begin{array}{l}\text { Early phase: large, dilated, densely } \\
\text { packed choroidal vessels. Mid-to } \\
\text { late-phase: choroidal vascular } \\
\text { hyperpermeability (focal or multi- } \\
\text { focal hyperfluorescent staining with } \\
\text { indistinct borders). }\end{array}$ & $\begin{array}{l}\text { Early phase: } \\
\text { hyperfluorescence. Early- } \\
\text { to-mid-phase: } \\
\text { hypofluorescence. }\end{array}$ & $\begin{array}{l}\text { Mixed pattern of fluorescence, } \\
\text { blockage of fluorescence in } \\
\text { pigmented lesions }\end{array}$ \\
\hline
\end{tabular}

${ }^{a}$ Choroidal melanoma serves as an example of choroidal malignancies in this table. Other tumors such as metastatic deposits or choroidal lymphoma have different clinical and imaging characteristic and should also be borne in mind

with inflammatory infiltrates. Choroidal vasculitis, onion skin thickening with occlusion of vessels, and adjacent focal RPE-lesions were also observed. Riono et al. reported multiple foci of non-necrotizing granulomatous inflammation of the choroid in one case of anterior scleritis with histologic features characteristic of sarcoidrelated granulomatous inflammation [46]. A case report by Stacy et al. of a chorioretinal biopsy specimen in idiopathic progressing posterior necrotizing chorioretinitis confirmed diffuse granulomatous inflammation of the inner scleral layers with a small focus of necrosis, consistent with idiopathic autoimmune scleritis [47].

Further evidence of choroidal involvement can be observed by indocyanine green angiography (ICGA) changes in patients with posterior scleritis. Auer and Herbort reported the ICGA patterns that can be 
observed in patients with posterior scleritis, and identified areas of diffuse zonal choroidal ICG hyperfluorescence in the intermediate and late phases, presumably corresponding to the areas of maximal inflammatory activity [48]. These areas of ICG hyperfluorescence were reported to regress in response to treatment. ICGA can thus be a useful imaging modality to assess the extent of choroidal involvement, and to monitor disease progression and response to treatment.

For the purpose of this review choroidal involvement is divided into four categories based on clinical observations: (1) choroidal thickness, (2) choroidal vasculitis, (3) presentation as a choroidal or subretinal mass in nodular posterior scleritis, and (4) choroidal folds, choroidal effusion and exudative retinal detachment. These categories are not mutually exclusive and represent the spectrum of choroidal involvement in posterior scleritis.

\section{Choroidal thickness}

While increased thickness of the posterior coats $(>2.0$ $\mathrm{mm}$ ) on B-scan ultrasound is a well-recognised diagnostic finding in posterior scleritis [21, 24, 25, 29], the involvement of the choroid in this process is less well studied. Recently, enhanced-depth imaging optical coherence tomography (EDI-OCT) has been used to characterise choroidal thickness in patients with posterior scleritis (Fig. 1). In a retrospective review published by Ando et al. subfoveal choroidal thickness, measured with EDI-OCT, was increased at presentation; and decreased with successful treatment during the follow-up period (mean choroidal thickness at presentation was $611 \pm 148 \mu \mathrm{m}$, decreasing to $298 \pm 75 \mu \mathrm{m}(p<0.01)$ at 1 month, and further decreasing afterwards) [14]. Dong and colleagues reported similar findings in a retrospective study of 23 patients with posterior scleritis and concurrent serous retinal detachment [20]. This case series showed an average subfoveal choroidal thickness with EDI-OCT of $442.61 \pm 55.6 \mu \mathrm{m}$ in the affected eye and $246 \pm 42.3 \mu \mathrm{m}$ in the unaffected eye $(p<0.01)$ and reported a significant correlation between subfoveal choroidal thickness and posterior coats thickness (as measured on B-scan ultrasound; $r=0.783, p<0.001$ ) and between subfoveal choroidal thickness and axial length $(\mathrm{r}=-0.65, p=0.001)$. Smaller case series confirm a marked subfoveal choroidal thickening in affected eyes with active posterior scleritis, with decreasing choroidal thickness after initiation of successful treatment, and increasing thickness if relapses occur $[49,50]$. These results suggest that subfoveal choroidal thickness, measured with EDI-OCT, can be used as a biomarker
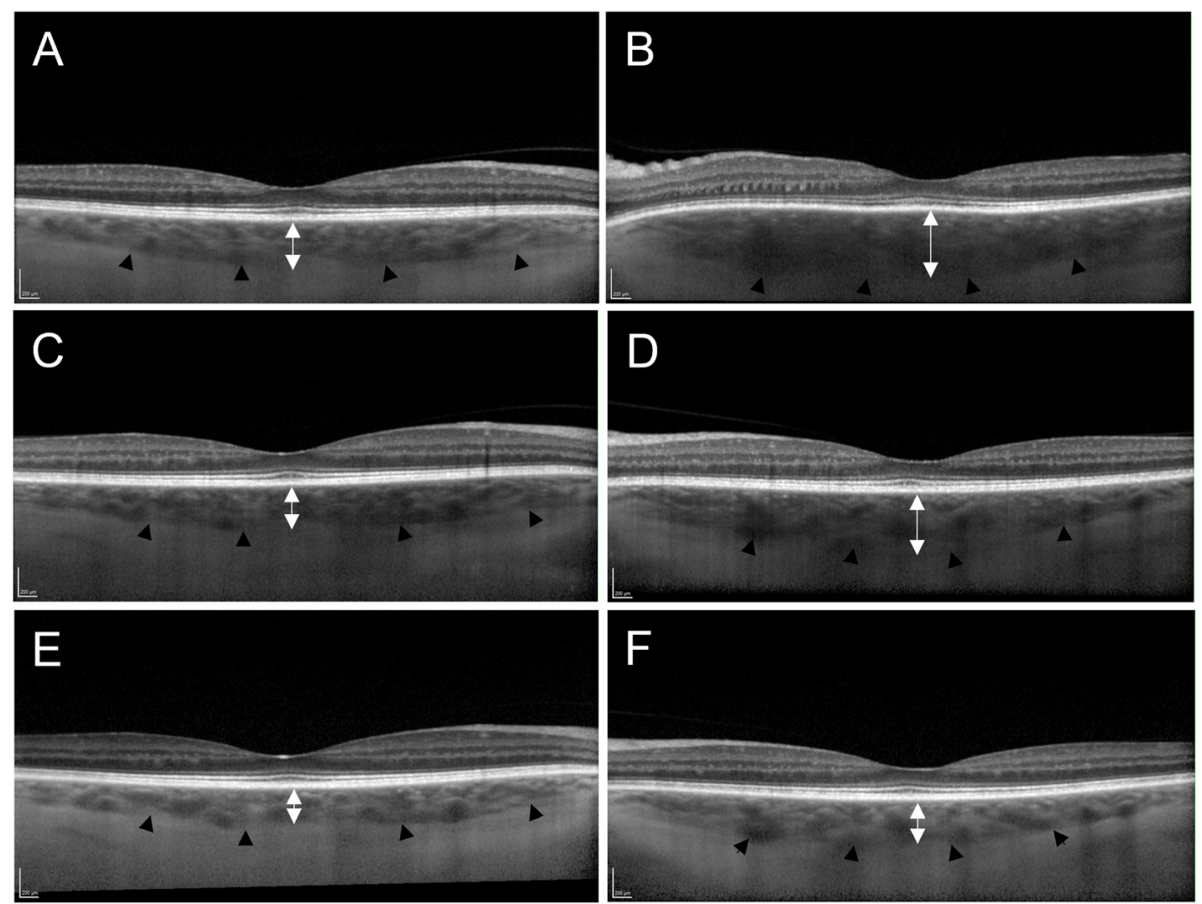

Fig. 1 Enhanced-depth imaging optical coherence tomography (EDI-OCT) in a case of left posterior scleritis. The black arrow heads delineate the choroidalscleral junction. (B) Spectralis EDI-OCT demonstrates left subfoveal choroidal thickening on presentation $(442 \mu \mathrm{m})$. The B-scan ultrasound showed thickening of posterior coats (2.5mm) and fluid in Tenon's capsule and optic nerve sheath (not shown). (D) Subfoveal choroidal thickness in the left eye decreased 1 week $(406 \mu \mathrm{m})$ and $(\mathbf{F}) 4$ weeks $(292 \mu \mathrm{m})$ after initiation of oral prednisolone. (A,C,E) Normal subfoveal choroidal thickness in the clinically unaffected right eye of the same patient at corresponding points in time 
for disease activity. This can be useful in diagnosing posterior scleritis and in monitoring the response to treatment. In eyes with frequent recurrences of posterior scleritis, choroidal thinning has been observed compared to the non-affected eye $[50,51]$. This is presumed to be due to gradual choroidal atrophy due to severe or recurrent inflammation of the posterior sclera $[50,51]$.

\section{Choroidal vasculitis}

Histopathological examination of scleral biopsies of patients with posterior scleritis can show active scleral vasculitis, as well as choroidal vasculitis, choroidal vascular closure and retinal vascular cuffing [18].

Adjacent choroidal changes in posterior scleritis can be evident on ICGA. Diffuse zonal choroidal ICG hyperfluorescence in intermediate and late phases was seen in all cases reported by Auer and Herbort, and regressed after anti-inflammatory treatment [48]. It could thus be hypothesized that the observed ICG hyperfluorescence is a representation of choroidal vasculitis adjacent to areas with active scleral inflammation. Other patterns that can be observed on ICGA in posterior scleritis are fluorescing pinpoints in the zonal hyperfluorescent areas, choroidal perfusion delay, enlargement of draining choroidal veins, and hypofluorescent dark dots up to the intermediate phase of the angiogram [48].

Choroidal vasculitis has been reported in a case report of nodular posterior scleritis associated with polyarteritis nodosa, and was evident on ICGA (segmental choroidal vessel staining and late leakage without choroidal ischemia) and OCT (hyperreflective thickening of the inflamed choroidal vessel wall) [52]. The authors reported disappearance of the choroidal vessel wall hyperreflectivity on OCT after anti-inflammatory treatment.

\section{Presentation as a choroidal or subretinal mass}

Nodular posterior scleritis can present clinically as a choroidal or subretinal mass (Fig. 2), and can be difficult to differentiate from malignant choroidal tumors [13, 16]. Clinical characteristics can help differentiation: nodular posterior scleritis tends to be unilateral, can be associated with an underlying systemic disease, and is associated with intraocular inflammation in the majority of cases [13]. Moreover, nodular posterior scleritis is often associated with choroidal folds or macular edema, and can be seen as a solitary amelanotic mass without the presence of lipofuscin or drusen [13]. An overlying bullous serous retinal detachment with shifting fluid can be present [15]. B-scan ultrasonography is the key imaging investigation: nodular posterior scleritis presents as a solitary sessile or dome-shaped lesion with high internal reflectivity, associated subretinal fluid or a $\mathrm{T}$-sign and no detectable blood flow [13].

Although pain is an important diagnostic element, it should be kept in mind, as mentioned above, that pain can be absent in posterior scleritis. It is therefore not a good differentiator between posterior scleritis and malignant choroidal tumors. If the diagnosis remains uncertain despite extensive noninvasive testing a choroidal biopsy may be required.

\section{Choroidal folds, choroidal effusion and exudative retinal detachment}

An exudative retinal detachment (ERD), or serous retinal detachment (Fig. 3), develops when fluid collects in the subretinal space due to disruption of the blood-retinal barrier [53]. This can be a complication of different types of ocular inflammation. In a retrospective review of uveitis-related ERD cases, Kinast and colleagues found that a serous retinal detachment was reported most frequently in Vogt-Koyanagi-Harada (VKH) disease (48.7\%), while posterior scleritis was observed in $2.6 \%$ of all uveitisrelated ERD-cases [54]. A similar result was found by Shah et al., who found 176 of 14,612 eyes (1.2\%) with ocular inflammation presented with ERD [55]. The most frequent type of inflammation associated with ERD in this cohort
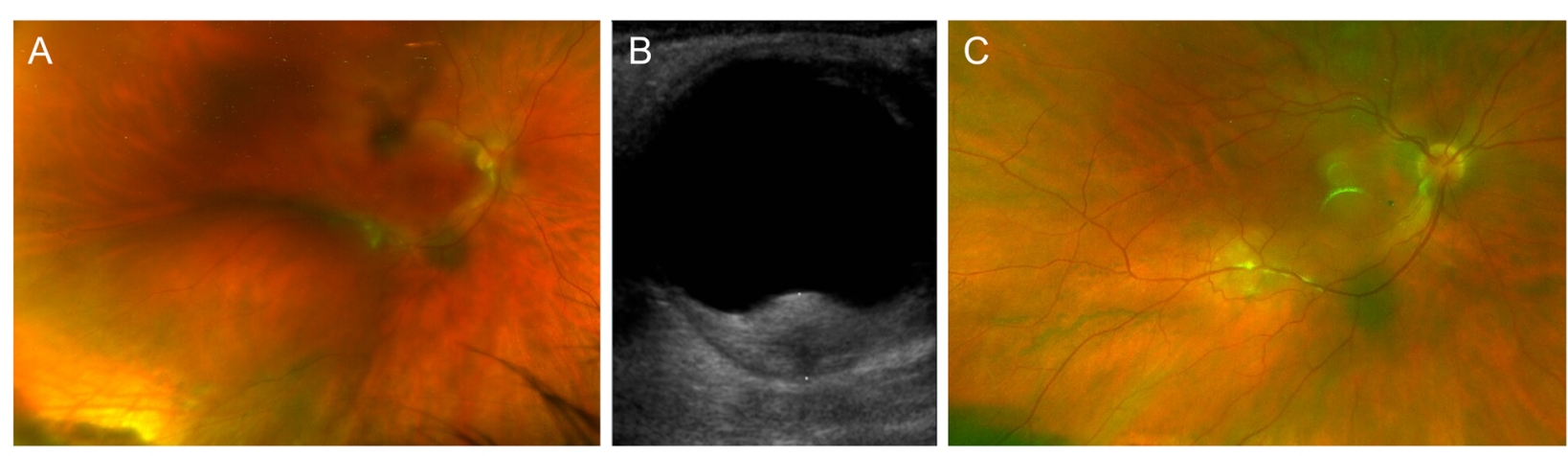

Fig. 2 Selected imaging findings in nodular posterior scleritis. (A) Pseudocolour fundus photograph of nodular posterior scleritis. (B) Corresponding B-scan ultrasound findings, showing gross thickening of the posterior coats $(6.6 \mathrm{~mm})$ with increased echogenicity. An ab externo biopsy was negative for malignancy. (C) The nodular lesion resolved with topical and systemic steroids, and Rituximab-infusions 

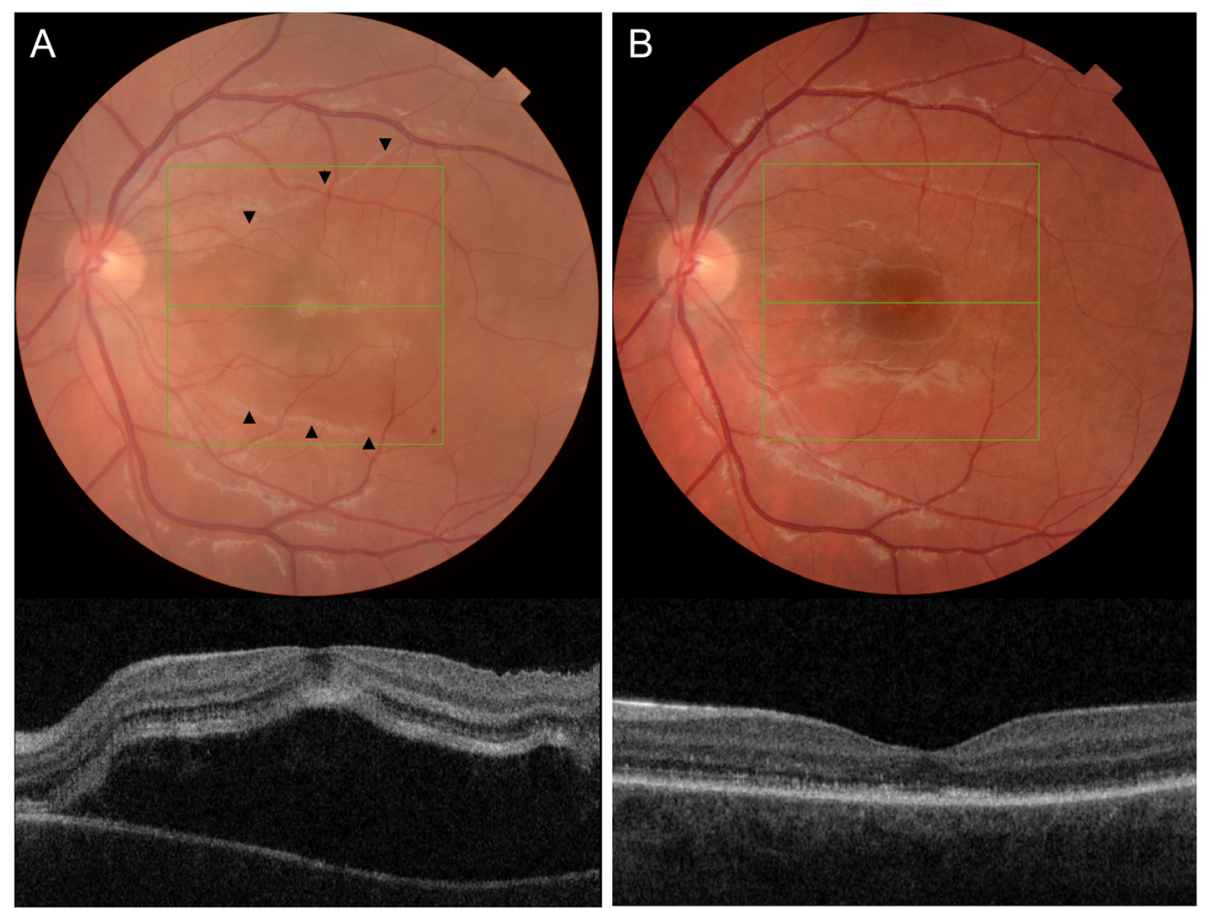

Fig. 3 Serous macular detachment secondary to posterior scleritis. (A) Colour fundus photograph and Topcon optical coherence tomography (OCT) at presentation. Delineation of the exudative detachment can be seen on the colour fundus photograph (black arrowheads). (B) Resolution of the serous macular detachment 3 weeks after initiation of oral prednisolone

was VKH as well (39.2\%), while posterior scleritis was observed in $4.0 \%$. Differentiating between VKH and posterior scleritis can be difficult, and a few case reports suggest the concurrent presence of both entities $[41,56,57]$.

Inflammation of the sclera can lead to reduced permeability of the transscleral outflow, resulting in fluid accumulation in the choroid, while thickening of the sclera can contribute to compression of the vortex veins and thus cause hyperpermeability and congestion of choroidal veins, eventually creating a choroidal detachment [22].

The presence of choroidal folds, choroidal effusion and serous retinal detachment in patients with posterior scleritis varies between the retrospective cohort studies. Lavric and colleagues report choroidal folds and serous retinal detachments in $28.1 \%$ each [24]. Serous retinal detachments are, however, less frequently observed in posterior scleritis cases as reported by McCluskey et al. (21.0\%), with choroidal effusion reported in 4.0\% [25]. A higher prevalence of serous retinal detachments (39.1\%) is observed by Calthorpe et al., with a ring choroidal detachment in $14.1 \%$ and choroidal folds reported in $10.9 \%$ in this retrospective study [18]. Benson and colleagues divided the clinical signs in their case series of posterior scleritis into different categories: 6 patients were observed to have choroidal folds, 7 patients had retinal striae and 1 had disc edema; furthermore an annular choroidal detachment was found in 7 patients, an exudative macular detachment in 15 patients, and a peripheral retinal detachment in one patient [15]. Dong et al. analyzed the clinical features of patients with a serous retinal detachment due to posterior scleritis [20]. In this retrospective study, a relatively young age at disease onset was reported (mean age 29.5 years old). Anterior scleritis was present in $52.0 \%$ of cases, which seems to be higher than in reports of posterior scleritis without serous retinal detachment [20]. Interestingly, Dong and colleagues reported that $74 \%$ of the patients in their study were initially misdiagnosed, underlining the importance of taking into account the clinical and imaging characteristics in such cases.

\section{Conclusion}

A spectrum of choroidal changes in posterior scleritis can be observed. Active posterior scleritis can be associated with increased subfoveal choroidal thickness, which reduces again in response to anti-inflammatory treatment. Subfoveal choroidal thickness can thus be used as a biomarker for disease activity. The current evidence to support this is limited, and further studies are warranted to determine the prevalence of these findings and to corroborate the use of EDI-OCT in diagnosing and monitoring disease activity. Choroidal vasculitis can be seen on ICGA and possibly also on OCT. No studies were identified using OCT-angiography (OCTA) to characterize posterior 
scleritis, while this could potentially prove useful as suggested by the finding of a different degree of vascularity and tissue thickness with anterior-segment OCTA in anterior scleritis [58]. A high level of suspicion is warranted in cases of nodular scleral inflammation leading to the presentation of a choroidal or subretinal mass, as these can be difficult to discern from a malignant choroidal tumor. Clinical and imaging characteristics can be useful in differentiating a rather benign, inflammatory cause from a malignant process. Further studies are needed to better identify the role of new imaging modalities such as EDI-OCT and OCTA in diagnosing and monitoring posterior scleritis.

\begin{abstract}
Abbreviations
Anti-TNF-a: Anti-tumor necrosis factor alpha; CSC: Central serous chorioretinopathy; EDI-OCT: Enhanced-depth imaging optical coherence tomography; ERD: Exudative retinal detachment; FA: Fluoresceine angiography; ICGA: Indocyanine green angiography; MR: Magnetic Resonance; MRI: Magnetic Resonance Imaging; NSAIDs: Non-steroidal antiinflammatory drugs; OCT: Optical coherence tomography; OCTA: OCTangiography; RPE: Retinal pigment epithelium; SRF: Subretinal fluid; VKH: Vogt-Koyanagi-Harada disease
\end{abstract}

\section{Acknowledgements}

None.

\section{Authors'contributions}

Sandra Vermeirsch - Conceptualization, Writing - Original Draft. Ilaria Testi Conceptualization, Writing - Original Draft. Carlos Pavesio -Conceptualization, Supervision, Writing - Review \& Editing. The author(s) read and approved the final manuscript.

\section{Funding}

This work was supported by the National Institute for Health Research (NIHR) Biomedical Research Centre based at Moorfields Eye Hospital NHS Foundation Trust and UCL Institute of Ophthalmology. The views expressed are those of the authors and not necessarily those of the NHS, the NIHR or the Department of Health.

\section{Availability of data and materials}

Not applicable.

\section{Declarations}

Ethics approval and consent to participate

Not applicable.

\section{Consent for publication}

Not applicable.

\section{Competing interests}

The authors have no relevant affiliations or financial involvement with any organization or entity with a financial interest in or financial conflict with the subject matter or materials discussed in the manuscript. This includes employment, consultancies, honoraria, stock ownership or options, expert testimony, grants or patents received or pending, or royalties.

Received: 27 August 2021 Accepted: 22 September 2021

Published online: 27 October 2021

\section{References}

1. Watson PG, Hayreh SS (1976) Scleritis and episcleritis. Br J Ophthalmol 60(3): 163-191. https://doi.org/10.1136/bjo.60.3.163

2. Berchicci L, Miserocchi E, Di Nicola M, La Spina C, Bandello F, Modorati G (2014) Clinical features of patients with episcleritis and scleritis in an Italian tertiary care referral center. Eur J Ophthalmol 24(3):293-298. https://doi. org/10.5301/ejo.5000394

3. Bin Ismail MA, Lim RHF, Fang HM, Wong EPY, Ling HS, Lim WK, Teoh SC, Agrawal R (2017) Ocular autoimmune systemic inflammatory infectious study (OASIS)-report 4: analysis and outcome of scleritis in an east Asian population. J Ophthalmic Inflamm Infect 7(1):6. https://doi.org/10.1186/ s12348-017-0124-5

4. Erkanli L, Akova YA, Guney-Tefekli E, Tugal-Tutkun I (2010) Clinical features, prognosis, and treatment results of patients with scleritis from 2 tertiary eye care centers in Turkey. Cornea. 29(1):26-33. https://doi.org/10.1097/ICO. Ob013e3181ac9fad

5. Keino H, Watanabe T, Taki W, Nakashima C, Okada AA (2010) Clinical features and visual outcomes of Japanese patients with scleritis. $\mathrm{Br} J$ Ophthalmol 94(11):1459-1463. https://doi.org/10.1136/bjo.2009.171744

6. Lane J, Nyugen E, Morrison J, Lim L, Stawell R, Hodgson L, Bin Ismail MA, Ling HS, Teoh S, Agrawal R, Mahendradas P, Hari P, Gowda PB, Kawali A, McCluskey PJ (2019) Clinical features of Scleritis across the Asia-Pacific region. Ocul Immunol Inflamm 27(6):920-926. https://doi.org/10.1080/09273 948.2018 .1484496

7. Dutta Majumder P, Agrawal R, McCluskey P, Biswas J (2020) Current approach for the diagnosis and Management of Noninfective Scleritis. AsiaPac J Ophthalmol Phila Pa 10(2):212-223. https://doi.org/10.1097/APO. 0000000000000341

8. Rahman Z, Jafarullah O, Huq N, Hasan K, Magesan K, Dutta MP (2020) Clinical profile of patients with Scleritis in Bangladesh. Ocul Immunol Inflamm Published online March 4:1-4. https://doi.org/10.1080/09273948.2 020.1716026

9. Sainz de la Maza M, Molina N, Gonzalez-Gonzalez LA, Doctor PP, Tauber J, Foster CS (2012) Clinical characteristics of a large cohort of patients with scleritis and episcleritis. Ophthalmology. 119(1):43-50. https://doi.org/10.101 6/j.ophtha.2011.07.013

10. Tanaka R, Kaburaki T, Ohtomo K, Takamoto M, Komae K, Numaga J, Fujino Y, Aihara M (2018) Clinical characteristics and ocular complications of patients with scleritis in Japanese. Jpn J Ophthalmol 62(4):517-524. https://doi.org/1 0.1007/s10384-018-0600-y

11. Tuft SJ, Watson PG (1991) Progression of scleral disease. Ophthalmology. 98(4):467-471. https://doi.org/10.1016/s0161-6420(91)32269-3

12. Yang P, Ye Z, Tang J, du L, Zhou Q, Qi J, Liang L, Wu L, Wang C, Xu M, Tian Y, Kijlstra A (2018) Clinical features and complications of Scleritis in Chinese patients. Ocul Immunol Inflamm 26(3):387-396. https://doi.org/10.1080/092 73948.2016.1241282

13. Agrawal R, Lavric A, Restori M, Pavesio C, Sagoo MS (2016) NODULAR POSTERIOR SCLERITIS: Clinico-sonographic characteristics and proposed diagnostic criteria. Retina Phila Pa. 36(2):392-401. https://doi.org/10.1097/IA E.0000000000000699

14. Ando Y, Keino H, Nakayama M, Watanabe T, Okada AA (2020) Clinical features, treatment, and visual outcomes of Japanese patients with posterior Scleritis. Ocul Immunol Inflamm 28(2):209-216. https://doi.org/10.1 080/09273948.2019.1574838

15. Benson WE (1988) Posterior scleritis. Surv Ophthalmol 32(5):297-316. https:// doi.org/10.1016/0039-6257(88)90093-8

16. Benson WE, Shields JA, Tasman W, Crandall AS (1979) Posterior scleritis. A cause of diagnostic confusion. Arch Ophthalmol Chic III 1960 97(8):14821486. https://doi.org/10.1001/archopht.1979.01020020144012

17. Biswas J, Mittal S, Ganesh SK, Shetty NS, Gopal L (1998) Posterior scleritis: clinical profile and imaging characteristics. Indian J Ophthalmol 46(4):195-202

18. Calthorpe CM, Watson PG, McCartney AC (1988) Posterior scleritis: a clinical and histological survey. Eye Lond Engl 2(Pt 3):267-277. https://doi.org/10.1 038/eye.1988.52

19. Cheung CMG, Chee S-P (2012) Posterior scleritis in children: clinical features and treatment. Ophthalmology. 119(1):59-65. https://doi.org/10.1016/j. ophtha.2011.09.030

20. Dong Z-Z, Gan Y-F, Zhang Y-N, Zhang Y, Li J, Zheng H-H (2019) The clinical features of posterior scleritis with serous retinal detachment: a retrospective clinical analysis. Int J Ophthalmol 12(7):1151-1157. https://doi.org/10.18240/ ijo.2019.07.16

21. Gonzalez-Gonzalez LA, Molina-Prat N, Doctor P, Tauber J, Sainz de la Maza M, Foster CS (2014) Clinical features and presentation of posterior scleritis: a report of 31 cases. Ocul Immunol Inflamm 22(3):203-207. https://doi.org/1 0.3109/09273948.2013.840385 
22. González-López JJ, Lavric A, Dutta Majumder P, Bansal N, Biswas J, Pavesio C, Agrawal R (2016) Bilateral posterior Scleritis: analysis of 18 cases from a large cohort of posterior Scleritis. Ocul Immunol Inflamm 24(1):16-23. https://doi.org/10.3109/09273948.2015.1045085

23. Kumar A, Ghose A, Biswas J, Majumder PD (2018) Clinical profile of patients with posterior scleritis: a report from eastern India. Indian J Ophthalmol 66(8):1109-1112. https://doi.org/10.4103/ijo.IJO_121_18

24. Lavric A, Gonzalez-Lopez JJ, Majumder PD, Bansal N, Biswas J, Pavesio C, Agrawal R (2016) Posterior Scleritis: analysis of epidemiology, clinical factors, and risk of recurrence in a cohort of 114 patients. Ocul Immunol Inflamm 24(1):6-15. https://doi.org/10.3109/09273948.2015.1005240

25. McCluskey PJ, Watson PG, Lightman S, Haybittle J, Restori M, Branley M (1999) Posterior scleritis: clinical features, systemic associations, and outcome in a large series of patients. Ophthalmology. 106(12):2380-2386. https://doi.org/10.1016/S0161-6420(99)90543-2

26. Rosenbaum JT, Robertson JE (1993) Recognition of posterior scleritis and its treatment with indomethacin. Retina Phila Pa. 13(1):17-21. https://doi.org/1 0.1097/00006982-199313010-00005

27. Singh G, Guthoff R, Foster CS (1986) Observations on long-term follow-up of posterior scleritis. Am J Ophthalmol 101(5):570-575. https://doi.org/10.1 016/0002-9394(86)90947-5

28. Wald KJ, Spaide R, Patalano VJ, Sugin S, Yannuzzi LA (1992) Posterior scleritis in children. Am J Ophthalmol 113(3):281-286. https://doi.org/10.1016/s00029394(14)71579-x

29. Okhravi N, Odufuwa B, McCluskey P, Lightman S (2005) Scleritis. Surv Ophthalmol 50(4):351-363. https://doi.org/10.1016/j.survophthal.2005.04.001

30. Ikeda N, Ikeda T, Nomura C, Mimura O (2007) Ciliochoroidal effusion syndrome associated with posterior scleritis. Jpn J Ophthalmol 51(1):49-52. https://doi.org/10.1007/s10384-006-0398-x

31. Maruyama I, Ohguro H, Nakazawa M (2002) A case of acute angle-closure glaucoma secondary to posterior scleritis in patient with Sturge-weber syndrome. Jpn J Ophthalmol 46(1):74-77. https://doi.org/10.1016/s0021-51 55(01)00463-4

32. Fourman S (1989) Angle-closure glaucoma complicating ciliochoroidal detachment. Ophthalmology. 96(5):646-653. https://doi.org/10.1016/s01616420(89)32850-8

33. Quinlan MP, Hitchings RA (1978) Angle-closure glaucoma secondary to posterior scleritis. Br J Ophthalmol 62(5):330-335. https://doi.org/10.1136/ bjo.62.5.330

34. Wilhelmus KR, Grierson I, Watson PG (1981) Histopathologic and clinical associations of scleritis and glaucoma. Am J Ophthalmol 91(6):697-705. https://doi.org/10.1016/0002-9394(81)90001-5

35. Fiebai B, Padhi TR, Panda KG, Modi RR (2015) Posterior scleritis with retinal pigment epithelium rip: an unusual presentation. Int Ophthalmol 35(1):141144. https://doi.org/10.1007/s10792-014-0031-9

36. Shukla D, Agrawal D, Dhawan A, Ramchandani B (2009) Posterior scleritis presenting with simultaneous branch retinal artery occlusion and exudative retinal detachment. Eye Lond Engl. 23(6):1475-1477. https://doi.org/10.1038/ eye.2008.217

37. Shukla D, Mohan KC, Rao N, Kim R, Namperumalsamy P, Cunningham ET (2004) Posterior scleritis causing combined central retinal artery and vein occlusion. Retina Phila Pa 24(3):467-469. https://doi.org/10.1097/00006982-2 00406000-00025

38. Sahu DK, Rawoof AB (2000) Cilioretinal artery occlusion in posterior scleritis. Retina Phila Pa. 20(3):303-305. https://doi.org/10.1097/00006982-20000300000015

39. Goldman DR, Johnson MW, Sarraf D (2012) Stellate neuroretinitis associated with posterior scleritis. Retin Cases Brief Rep 6(2):163-165. https://doi.org/1 0.1097/ICB.0b013e318223538

40. van Dijk EHC, Boon CJF (2021) Serous business: Delineating the broad spectrum of diseases with subretinal fluid in the macula. Prog Retin Eye Res. Published online March 11 84:100955. https://doi.org/10.1016/j.preteyeres.2 021.100955

41. Moon SY, Yoon WT, Park SP (2015) Recurrent unilateral Vogt-KoyanagiHarada disease with posterior Scleritis. Korean J Ophthalmol KJ 29(5):352354. https://doi.org/10.3341/kjo.2015.29.5.352

42. Diogo MC, Jager MJ, Ferreira TA (2016) CT and MR imaging in the diagnosis of Scleritis. AJNR Am J Neuroradiol 37(12):2334-2339. https://doi.org/10.31 74/ajnr.A4890
43. Cordero-Coma M, García-Morán A, Yilmaz T, Sánchez-Campos S, CallejaAntolín S, Martín-Escuer B, Martin S, Ruiz de Morales JG (2011) Adjunctive globe magnetic resonance imaging in the diagnosis of posterior scleritis. Can J Ophthalmol J Can Ophtalmol 46(4):329-332. https://doi.org/10.1016/j. jcjo.2011.06.009

44. Osman Saatci A, Saatci I, Kocak N, Durak I (2001) Magnetic resonance imaging characteristics of posterior scleritis mimicking choroidal mass. Eur J Radiol 39(2):88-91. https://doi.org/10.1016/s0720-048x(01)00278-9

45. Stem MS, Todorich B, Faia $\sqcup$ (2017) Ocular pharmacology for Scleritis: review of treatment and a practical perspective. J Ocul Pharmacol Ther Off J Assoc Ocul Pharmacol Ther 33(4):240-246. https://doi.org/10.1089/jop.2016.0127

46. Riono WP, Hidayat AA, Rao NA (1999) Scleritis: a clinicopathologic study of 55 cases. Ophthalmology. 106(7):1328-1333. https://doi.org/10.1016/S01616420(99)00719-8

47. Stacy RC, Uchiyama E, Jakobiec FA, Sobrin L (2015) Posterior necrotizing Scleritis presenting as sectoral Chorioretinitis. Ocul Immunol Inflamm 23(5): 412-415. https://doi.org/10.3109/09273948.2014.896467

48. Auer C, Herbort CP (1998) Indocyanine green angiographic features in posterior scleritis. Am J Ophthalmol 126(3):471-476. https://doi.org/10.1016/ s0002-9394(98)00119-6

49. Hirukawa K, Keino H, Watanabe T, Okada AA (2013) Enhanced depth imaging optical coherence tomography of the choroid in new-onset acute posterior scleritis. Graefes Arch Clin Exp Ophthalmol Albrecht Von Graefes Arch Klin Exp Ophthalmol 251(9):2273-2275. https://doi.org/10.1007/s00417013-2265-z

50. Uchihori H, Nakai K, Ikuno Y, Gomi F, Hashida N, Jo Y, Nishida K (2014) Choroidal observations in posterior scleritis using high-penetration optical coherence tomography. Int Ophthalmol 34(4):937-943. https://doi.org/10.1 007/s10792-013-9894-4

51. Taki W, Keino H, Watanabe T, Okada AA (2013) Enhanced depth imaging optical coherence tomography of the choroid in recurrent unilateral posterior scleritis. Graefes Arch Clin Exp Ophthalmol Albrecht Von Graefes Arch Klin Exp Ophthalmol 251(3):1003-1004. https://doi.org/10.1007/s00417012-1972-1

52. Ramtohul P, Comet A, Denis D (2020) Segmental choroidal Vasculitis in nodular posterior Scleritis associated with Polyarteritis Nodosa. Retina Phila Pa. 40(10):e58-e59. https://doi.org/10.1097//AE.0000000000002907

53. Amer R, Nalcı H, Yalçındağ N (2017) Exudative retinal detachment. Surv Ophthalmol 62(6):723-769. https://doi.org/10.1016/j.survophthal.2017.05.001

54. Kinast RM, Solomon SD, Cubillan LD, Hovakimyan A, Acharya N, Cunningham ET. Prevalence and causes of clinically detectable uveitic serous retinal detachment. Eur J Ophthalmol. Published online February 2, 2021:1120672121991391. doi:https://doi.org/10.1177/1120672121991391

55. Shah DN, Al-Moujahed A, Newcomb CW et al (2020) Exudative retinal detachment in ocular inflammatory diseases: risk and predictive factors. Am J Ophthalmol 218:279-287. https://doi.org/10.1016/j.ajo.2020.06.019

56. Kouda N, Sasaki H, Harada S, Yamada Y, Takahashi N, Sasaki K (2002) Early manifestation of vogt-koyanagi-harada disease as unilateral posterior scleritis. Jpn J Ophthalmol 46(5):590-593. https://doi.org/10.1016/s0021-51 55(02)00545-2

57. Watanabe K, Kato T, Hayasaka S (1997) Concurrent bilateral posterior scleritis and Vogt-Koyanagi-Harada disease in a patient with positive rheumatoid factor. Ophthalmol J Int Ophtalmol Int J Ophthalmol Z Augenheilkd 211(5): 316-319. https://doi.org/10.1159/000310817

58. Hau SC, Devarajan K, Ang M (2021) Anterior segment optical coherence tomography angiography and optical coherence tomography in the evaluation of Episcleritis and Scleritis. Ocul Immunol Inflamm 29(2):362-369. https://doi.org/10.1080/09273948.2019.1682617

\section{Publisher's Note}

Springer Nature remains neutral with regard to jurisdictional claims in published maps and institutional affiliations. 